\title{
Global and Local Perspectives on the Preservation of Linguistic Diversity: A Nepali Experience*
}

\author{
Min Pun \\ Associate Professor of English \\ Prithvi Narayan Campus, Pokhara \\ minpun@pncampus.edu.np
}

\begin{abstract}
This paper deals with the past studies about preserving and promoting linguistic diversity with special reference to indigenous languages of the world in general and of Nepal in particular. It is broadly divided into two major categories viz. global perspectives on linguistic diversity issues and local perspectives on linguistic diversity issues. The global perspectives section is related to conceptualizing the global trends of preserving and promoting linguistic diversity in different regions of the globe. For instance, past studies conducted on indigenous languages of Europe, South Asia (including Sri Lanka, Pakistan and India), Latin America, North America, Africa, and Malaysia were reviewed to identify the research gap for this study. The local perspectives section is related to conceptualizing the Nepali trends of preserving and promoting linguistic diversity in Nepal. Similarly, empirical studies were reviewed into four aspects such as a) linguistic diversity and multilingualism, $b$ ) endangerment of indigenous languages, c) bilingual and multilingual education, and d) mother tongue literacy. Based on these observations, this paper has been developed to identify the global and local perspectives on the preservation of linguistic diversity, using a Nepali experience.
\end{abstract}

Keywords: Endangered languages, indigenous languages, linguistic diversity, multilingualism.

\section{Introduction}

As in biodiversity, each species no matter how big or small has an important role to play to protect our environment; it is also necessary to preserve and promote linguistic diversity both

\footnotetext{
* Received: February 8, 2020

Peer Reviewed: July 3, 2020

Accepted: September 2, 2020
} 
in Nepal and in the world because languages are part of our history and are the means of our ancient cultures. So they can play vital roles in the overall development of Nepal.

The language issues raised in this paper are related to language endangerment and language maintenance that are indirectly associated with the national language policy of the government, minimizing the use of minority languages (Pun and Gurung 1). This is based on the use of language and is most severely felt by indigenous language communities across the world. Nepal is no exception. The paper has, therefore, aimed to suggest a more appropriate language policy of the government that can contribute to the preservation and promotion of indigenous languages of Nepal.

Thus, linguistic diversity is endangered by this trend now, and this danger is, in particular, severely felt by Nepal's indigenous communities. In Nepal, many languages of these communities such as the languages of Tibeto-Burman language family are in danger of extinction. According to linguists, languages are grouped as per the levels as safe, at risk, endangered and extinct (Crystal 20). If it is considered from this perspective, most indigenous languages of Nepal are believed to be in the endangered list.

In this paper, it is argued that not only the government, but also the older generation of indigenous peoples are responsible for decline and death of such languages of Nepal. For instance, the older generations consciously or unconsciously do not pass on their languages to their children. This is a serious setback for language revitalization efforts. In many cases, indigenous peoples who speak the Nepali language well are considered favorably as compared to those who speak their mother-tongues very well. Similarly, in all types of educational institutions, businesses, and media, the Nepali language is considered powerful medium to communicate each other. In this way, the indigenous language communities are discouraged to use their languages and even the older generation indigenous peoples failed to pass on their languages to their younger generations. Thus, the objective of this paper is to preserve and promote linguistic diversity, analyzing the linguistic situation of Nepal from the global and local perspectives and using a Nepali experience.

\section{Global Perspectives}

Linguistic diversity in the world today is an issue of growing social importance because majority of all living languages are endangered continuously. So multilingualism is a common and increasing phenomenon which can be studied from different perspectives. In a study of linguistic diversity and multilingualism in Europe, Durk Gorter et al. have tried to focus on language as a cultural asset and to establish the relationship between linguistic diversity and human welfare from an economic perspective. Their study has tested 48 states in Europe that have 38 different official state languages and about 240 spoken indigenous languages. Among them, 5 languages such as Russian, German, English, French and Italian are spoken by most 
people in Europe. European states such as Italy, the United Kingdom, Germany, Poland, France, Spain, Romania and Ukraine have many indigenous minority or regional languages. The study showed that except Russia, some of the minority languages in Europe have obtained official status. For instance, Basque, Catalan and Galician have official status in Spain; Welsh has protective language rights in the United Kingdom, as does Irish in Ireland, Frisian in the Netherlands and the Sami languages in Norway, Sweden and Finland (8). The study suggests that multilingualism is a common phenomenon in Europe though the linguistic diversity of Europe is not rich as in other continents. The study also found that only $3.5 \%$ of the world's total numbers of languages are indigenous to Europe, but Europeans feel their continent to have an exceptional number of languages as compared to North America and Australia (9). Interestingly, they have considered languages as part of the heritage of a specific community, creating its identity in the same way as its physical heritage does. In sum, languages need to be valued and preserved as we do with the cultural and environmental heritage of a region.

Many fear that less widespread languages are difficult to exist and survive in the world. So the preservation of linguistic diversity is necessary in order to maintain the flexibility and adaptability of a species. In this case, like the study by Durk Gorter et al., Arthur Wetzel argued that preserving linguistic diversity is worthwhile from an economic perspective. For instance, the ability to communicate in several languages is of great benefit to all employees in organizations and companies, promoting creativity, breaking down cultural clichés, encouraging unconventional thinking and contributing to the development of innovative products and services. Similarly, people who can speak two languages can have extra advantages in terms of mental performance, which are expressed in divergent thinking, creativity and communicative sensitivity (39). His study suggests that using new language technologies can help preserve indigenous languages. Thus, in the digital age, it is necessary for all to have joint obligation to invest in new technologies to preserve linguistic diversity and carry it into the future.

The studies made on the language endangerment and preservation in South Asia by various researchers reveal that South Asian countries are diverse in terms of languages, but they also feature prominently in the worldwide charts of linguistic endangerment. The authors included in the book consider language endangerment as a complex and multi-faceted issue and call for long-term approaches to language preservation (Cardoso 2). In a chapter compiled in the book, E. Annamalai illustrates a linguistic situation with Tamil, a South Asian language in which the language is still be spoken inter-generationally, but only for limited in-group communication. In the case, a language survives, but it does not live. It shows that due to its lack of economic value, its speakers consider the language a liability in education and for material progress, restricting it from functioning well (3). According to E. Annamalai, there is 
no threat to the survival of the Tamil language, but it is a threat to its functioning as a language, missing its dynamism and shrinking to become a vernacular only.

In the same book edited by Hugo C. Cordoso, Liudmila V. Khokhlova has studied the sociolinguistic status of Punjabi language in Pakistan in terms of languages that are at risk of falling out of use as their speakers die out or shift to some other languages. His study revealed the historical, economic, political, cultural, and psychological reasons for the gradual removal of a majority language from the repertoires of native speakers of Punjabi language in Pakistan (19). So the Punjabi language in Pakistan has gradually lost its rich vocabulary and the ability to fulfill the intellectual demands of society, leading to what is called intellectual death of the language.

Yet in another chapter of the same book on the language endangerment and language preservation in South Asia, Stephen Morey discusses two North East Indian languages: Tai Ahom and Tangsa on issues related to language maintenance and loss. In this study, he discovered that Tai Ahom and Tangsa languages have been spoken as a mother tongue for long, but survive in the large body of manuscripts, and in the language used in religious rituals. He argued that these features are necessary foundations of the ongoing revival of these two languages (46). Morey's study shows that different indigenous languages have their own way of language decline and language maintenance.

In the last chapter of the book, Umberto Ansaldo and Lisa Lim have studied the Malay language in Sri Lanka, discussing the origins of the language in terms of intense contact and multilingual transfer, and analyzing the forces that led to a significant language shift and consequent loss as well as the factors responsible for the recent survival of the language. The chapter discusses the ideologies of language upheld within the community and the role of external agents in the lifecycle of the community (100). The study by Ansaldo and Lim concludes that language shift and linguistic restructuring in minority languages will have two opposed trends: one, convergence to the dominant culture(s) and two, preservation of unique own identity.

In the context of globalization, the state of linguistic diversity is featured by various political and legal regulations of linguistic relations. A study on linguistic diversity in Russia by Dmitry V. Bondarenko et al. found that giving the status of state to a large number of languages in Russia does not guarantee political stability and national security (166). So the position of the Russian language should be restored, and the desire to create a single global language as a utopian and destructive phenomenon. They concluded that a balance must be found between the unique palette of linguistic diversity on the planet and the undeniable presence of several well-known world languages. The study also suggested adopting bilingual education as one of the harmonious and evolutionary ways to preserve linguistic diversity in Russia (166). It is 
clear from this study that, as Russian experience shows, only granting minority languages the status of the state language does not guarantee the survival of languages, so the desire to defend and preserve their identity with every means plays a significant role for the status of their languages.

Another study made on the preservation of linguistic diversity in Russia is from the Commission of the Russian Federation for UNESCO that aimed to produce the basic international document for the development of linguistic diversity on the Internet. The study has analyzed four interconnected aspects: 1) development of multilingual content and systems; 2) facilitating access to networks and services; 3 ) development of public domain content; and 4) reaffirming the equitable balance between the interests of rights-holders and the public interest (6). The focus of the study is to encourage multilingualism which is important for Russia not only with a view to preserving and promoting languages as the foundation of the cultural heritage of the different nations inhabiting Russia, but also addressing political, economic, social and other cultural problems of multiethnic and multilingual society such as Russia.

In North America, there is a growing concern over the issue of whether or not Native American cultures can survive without their language. A study conducted by Jeff Melton pointed out that Native languages are endangered with $73 \%$ of them currently facing near extinction, which is of great importance since loss of a language results in the loss of cultural identity and sovereignty. In order to reinforce the survival of language, he encouraged Native Americans to strengthen the survival of individual cultural identity and thus strengthen each individual culture's sovereignty. He also argued that both culture and sovereignty are at risk like many other native languages are facing the possibility of extinction (69). So he recommended that the Native Americans should be educated in the struggle for the survival of native languages. He also recommended that tribal schools and colleges should develop Native language classes and courses as part of their offered curriculum (75). For Melton, education has a new role in the struggle for the survival of Native languages.

In South America, the Guarani language is the official language of Paraguay, but not in Brazil although it is spoken by a large number of indigenous peoples in Brazil. In a study on the preservation of Guarani language, Francesca Xotta has analyzed the evolution of language rights made for indigenous peoples in Brazil. He has explored the link between linguistic rights and human rights by using a number of different sources from the United Nations (UN) and other institutions (3). He suggested that education can improve the linguistic standards of indigenous peoples, which is possible through participation and inclusion of minorities in public life such as education that is essential to fulfill indigenous rights. He also suggested 
focusing on the importance of public institutions that can help indigenous people preserve their traditional ways of living and their cultural identities.

In Africa, Zimbabwe is a multilingual nation with 16 officially recognized languages in the country's constitution where English is used in all official business at the expense of indigenous languages spoken by over $90 \%$ of the population. In a study on the attitudes towards the use of indigenous African languages as languages of instruction in schools, colleges and universities, Wiseman Magwa tested a total of 1000 participants who took part in the study comprising 200 teachers, 300 parents/guardians and 500 learners. The study revealed that English continues to be the prestige-laden language enjoying high while indigenous languages enjoy relatively low status (1). Study findings clearly show that the majority of the participants prefer English to be the medium of instruction in primary, secondary and tertiary education because it is a language that gives power and prestige. The study recommends a linguistic revolution and calls for a change in education policies so as to avoid the exclusion of the majority from public discourse, development and other issues of national significance.

In Malaysia, there are several indigenous groups whose native languages are dying. Now, there are only about 750 of them in the jungle. Since its independence, the Malaysian government has adopted strategies to unite its population that consisted of diverse ethnic groups and cultures, including their languages. Rohaty Mohd Majzub and Maisarah Muhammad Rais studied the responses of lecturers and university students towards the preservation of the endangered languages in Malaysia such as the Bateq language. The researchers tested thirty students and ten lecturers who involved in the focus group interview session. Their study found that the reasons for the preservation of endangered languages were 1) propagation of One Malaysia and Vision 2020, 2) death of the indigenous people, 3) diversity in Malaysia, 4) promotion of inclusivity, 5) cultural heritage and identity, 6) multiculturalism, 7) politicalsocial stability, 8) creativity of expression and inclusivity, and 9) globalization effects (1677). The study also found some barriers to preservation of endangered languages such as the majority versus minority issue, ignorance or lack of knowledge of the indigenous groups, physical inaccessibility, and lack of input from the indigenous groups. The results indicated high agreement on the need to preserve endangered languages of the ethnic minority in Malaysia. The findings recommended that policy makers and implementers need to develop educational and social programs to enhance the use of endangered languages through the curricular modification.

\section{Local Perspectives}

History has shown that the languages of dominant groups have always minimized the use of the languages of minority groups, in many cases, resulting in the extinction of such languages. As discussed in the previous paragraphs, due to globalization and changes in the 
global society, the languages of minority groups have become a topic of discussion among the linguists and language activists now.

In Nepal, very few linguists have researched on the language issues as the linguistic situation of Nepal is complex and lacks serious studies. So attempts made by some individual and group researchers are not sufficient to give a clear picture of the linguistic situation of Nepal. The following paragraphs examine the attempts made by Nepali and foreign linguists about the languages of Nepal.

In his paper entitled "Linguistic Surveys," Dan Raj Regmi has surveyed the languages of Nepal since 2009, analyzing the survey made by the Linguistic Survey of Nepal (LinSuN). His study has explored the progress, challenges and prospects of the survey conducted by the LinSuN (46). Accordingly, the LinSuN has surveyed eight languages so far and has prepared the draft reports of the survey. Although the LinSuN had trained manpower, tools and enthusiasm, it lacked sufficient budget to achieve its expected goals. So it is necessary to formulate appropriate language policy to address the current language issues, which should be based on the socio-linguistic perspective. The findings suggested the concerned authorities at home and abroad should help the LinSuN to complete the survey of the languages of Nepal. In order to preserve and promote languages of Nepal, his study concluded that there needs a comprehensive linguistic survey to identify and document the endangered minority languages, to determine their role in primary and adult education, to develop orthographies for unwritten languages, and to implement the socially inclusive provisions in Nepal.

There was a seminar on the linguistic situation of Nepal in 2005, which was organized by the National Foundation for Development of Indigenous Nationalities (NFDIN) based in Kathmandu. The theme of the seminar was the survey of language situation and the formulation of policies and planning for the preservation and promotion of indigenous languages and the main objective of the seminar was to establish coordination among various language-related national and international agencies.

In the seminar, three research papers were presented by Nepali and foreign linguists. The first paper was jointly presented by Yogendra P. Yadava and Mark Turin. The paper dealt with the indigenous languages of Nepal that examined two aspects of these languages such as language situation and language issues. The language situation covered the topics such as identification, distribution, genetic affiliation, writing systems, ethnicity and language endangerment. The second aspect of indigenous languages covered contemporary issues related to the preservation and promotion of linguistic diversity in Nepal, discussing various aspects such as ecology, state, law, census, media, education and gender (6). The paper indicated that there is always room for promotion of indigenous languages of Nepal. The paper also recommended that the language communities should launch campaigns to revitalize their 
languages and the government should frame language policies to increase the prestige and use of such languages, including in the education system. They also recommended that the language communities should be encouraged to develop the writing system, using the modern technology.

The second paper presented by David Watters and Noval K. Rai discussed the nature and scope of indigenous languages and recommended appropriate language policies and planning to improve the situation of such languages (74-75). The overall focus of the paper was to use indigenous languages at home and in schools that can help the indigenous peoples to connect to the wider language communities.

David Watters and Nirmal Man Tuladhar gave the third presentation that discussed the framework to establish coordination among various national and international agencies to launch language revitalization campaigns for the preservation and promotion of such languages (74). The paper was divided into three sections: the first section dealt with a list of agencies and individuals in language work in Nepal; the second suggested a model of cooperation that dealt with a group of people that share and collaborate in getting over problems; and the third made some specific suggestions about the form of the collaboration that included academics, practitioners and policy makers. The paper also suggested that support and coordination could be possible as individuals and organizations needed to have one.

Linguist Mark Turin has conducted a comprehensive research on the preservation of linguistic diversity. His study provides detailed information on linguistic diversity on matters related to endangerment and preservation that deals with the issues of linguistic and social context of Nepal (1). According to him, there is a relationship between language, culture, knowledge and ethnicity, dealing with the issues of marginalization, politics and linguistic ecology. Since the study is a case study from Nepal, its outcomes go beyond the Nepali context such as other multilingual societies across the Himalayan regions and beyond.

A study conducted by Pushker Kadel suggested the idea that the progress of a nation depends on the education system because languages used in schools and colleges contribute to the quality of education (190). His idea is related to the implementation of bilingual or multilingual education system in Nepal. He suggests that the education policies should address the minority language issues, which should be included in the basic education of Nepal. He further suggests that all language groups have the right to preserve and promote their languages, scripts, and cultural heritages (189-190). His findings suggest that each language community needs to choose bi- and multilingualism as a minimal requirement to teach children in the beginning stage of their education in order to create strong foundation in their life.

Like Pushker Kadel, the Department of English Education has surveyed seven schools from six different districts to identify the practice of multilingual education program. The study 
found that the multilingual education program cannot be sustainable because of its unrealistic implementation (7). According to his study, one of the reasons for this is that there is insufficient support from the teachers and the state. So it is recommended that the state should be serious about the implementation of the policies. The study concluded that the multilingual education situation in all schools found to be encouraging because the stakeholders wanted to continue with the multilingual education programs.

Similarly, another study on the ongoing bilingual education program conducted by the Department of Education, Government of Nepal indicated that it is helpful if the children are given education through their mother-tongues that minimizes the learning difficulties. As per the recommendations made by the Department, the government adopted the policy of teaching mother-tongue as an optional subject in schools, but it did not have any positive changes in the school education (2). Even the Curriculum Development Center (CDC) designed ten curricula and developed textbooks in different languages for that purpose. One of the main reasons for not having any positive impact of the government's efforts was the lack of qualified mothertongue teachers. Overall, it was found that the bilingual education was not effective. The Department recommended that in order to make the bilingual education program successful, the mother-tongue teachers should be trained to be good teachers. A similar study was conducted by Dan Raj Regmi who suggested that before having the bilingual/multilingual education program, it is necessary to formulate the multilingual language policy to encourage indigenous language groups to speak in their languages ("Convalescing the Endangered Languages" 139). According to Regmi, the speakers of indigenous languages should be given education in their mother-tongues if we want to preserve and promote indigenous languages.

The restoration of democracy in Nepal in 1990 is the turning point for the language revitalization campaigns. Many linguists and language activists took initiatives to advocate mother-tongue literacy in Nepal. For instance, many ethnic organizations even started developing literacy materials and conducted several language campaigns across Nepal. Even the constitutions of Nepal after 1990 have advocated bilingual/multilingual education program. In this respect, a study has investigated good practice in the development of mother-tongue literacy. It has also tried to find the ways to share this practice at the national level. The study has sampled four indigenous languages such as Tharu, Tamang, Newar, and Limbu as they have their literacy programs (Kadka 2-3). The findings indicated that, in the case of Newari language literacy program, a monolingual group can gain access to the official language of the wider society through literacy classes. In the case of Limbu language literacy program, it was found that the learners were motivated to join and actively participate in literacy classes, raising awareness of non-literate local people and helped to conserve the Limbu language and script. In the case of Tamang, the study showed that the learners had developed a habit of reading and writing after they participated in the mother tongue literacy program. In the case of Tharu, the 
findings showed that through the Nepali language the learners learnt their mother tongue quickly that promoted Tharu culture as a positive model for the development and use of cultural-mosaic materials.

Finally, Yogendra P. Yadava has made an important study on the languages of Nepal. His study is based on the census 2011 that has examined the situation of language diversity. He has grouped mother-tongues into two: the major language group that consisted of $96 \%$ of the total population and the minor language group that consisted of $4 \%$ of the total population (51). Overall, his study suggests that the formulation of language policy both at national and local levels by the state is needed and the use of mother-tongues in multilingual education in both formal and non-formal situation.

\section{Linguistic Diversity Issues: A Case of Nepal}

The paragraphs above on the global and local perspectives on the preservation of indigenous languages have reviewed the influence of Nepali language in Nepal, marginalizing other languages such as indigenous languages. It has looked at the effect it has on the languages spoken in Nepal. It has attempted to explain that even though the need for interconnectedness is relevant in view of the lingua franca operating today, there is still the need for linguistic diversity. As Min Bahadur Pun and Kamal Gurung argue in their study, "Ways have to be sought to maintain linguistic diversity and intercommunication needs of different groups of people" (16). So the essence of maintaining the God-given linguistic diversity is first for the need to respect the linguistic and fundamental human rights of all. Second, to preserve the indigenous languages all over, especially those spoken in Nepal.

The summary of the reviewed literature concluded that the result of Nepali language threatened the local languages in Nepal mostly due to the language policy of the government and partly due to the elders of indigenous peoples who do not pass their mother tongues to their children. A language is threatened, and could also be endangered, when it is not passed on to the new generation of children (Pun and Gurung 16). This is the position of most languages in Nepal today. Thus, more steps of preservation of the endangered languages have to be taken as language extinction has accelerated dramatically in recent years.

In summary, the literature review made in this paper are mainly based on the available data of languages from the census and the language revival efforts made by the subsequent governments of Nepal, linguists and language activists. Some reviews were based on the study of linguistic diversity, bilingual and multilingual education programs, and mother-tongue literacy programs. While the existing literature points to some efforts that have been made by individual linguists as well as organizations in order to preserve and promote linguistic diversity in Nepal that makes a body of linguistic research practice to be explored, there is 
nonetheless a scarcity of researches on indigenous languages of Nepal. In this paper, they were considered as informational and analytical problems.

\section{Conclusion}

The process of language endangerment is based solely on the language policy of the government, and is most severely felt by indigenous language communities of Nepal. This study has, thus, suggested a more appropriate language policy of the government that can accommodate indigenous languages of Nepal, contributing to the preservation and promotion of linguistic diversity in the world. Overall, the past studies showed that the indigenous language communities should be supported by the government for giving official status to their native languages, focused on formulation and implementation of education policies, and encouraged to insist on speaking their native languages. Most importantly, the indigenous language communities need to collaborate with the government to curb all the issues related to preserving and promoting linguistic diversity in Nepal.

\section{Acknowledgements}

This paper is built upon a research project entitled "Preserving and Promoting Linguistic Diversity in Nepal: A Case Study of Indigenous Languages from Kaski District" completed in 2020 in collaboration with the University Grants Commission, Nepal. I would like to thank everyone who has directly or indirectly involved in this project, supporting me to complete it.

\section{Works Cited}

Annamalai, E. "Death by Other Means: Neo-vernacularization of South Asian Languages." Language Endangerment and Preservation in South Asia, edited by Hugo C. Cardoso, U of Hawai'i P, 2014, pp. 3-18.

Ansaldo, Umberto, and Lisa Lim. "The Lifestyle of Sri Lanka Malay." Language Endangerment and Preservation in South Asia, edited by Hugo C. Cardoso, U of Hawai'i P, 2014, pp. 100-118.

Bondarenko, Dmitry V., Vladimir V. Nasonkin, Rozalina V. Shagieva, Olga N. Kiyanova, and Svetlana V. Barabanova. "Linguistic Diversity in Russia: Is a Threat to Sovereignty or a Condition of Cohesion?" Modern Journal of Language Teaching Methods (MJLTM), vol. 8, no. 5, 2018, pp. 166-182, www.mjltm.org

Cardoso, Hugo C. Foreword. Language Endangerment and Preservation in South Asia, edited by Hugo C. Cardoso, U of Hawai'i P, 2014, pp. 1-2.

Commission of the Russian Federation for UNESCO. Preservation of Linguistic Diversity: Russian Experience. UNESCO, 2008.

Crystal, David. Language Death. Cambridge UP, 2000. 
Department of Education, Government of Nepal. A Study on Bilingual Education, November 2001, www.doe.gov.np/assets/uploads/files/62d3fb33094586b0cfd22028a25bb2da.pdf

Department of English Education, Faculty of Education, TU. Multilingual Education in Nepal: Hearsay and Reality? UNESCO, 2011.

Gorter, Durk, Jasone Cenoz, Paulo Nunes, Patrizia Riganti, Laura Onofri, Barbara Puzzo, and Rajesh Sachdeva. "Cultural Diversity as an Asset for Human Welfare and Development: Benefits of Linguistic Diversity and Multilingualism." Sustainable Development in a Diverse World (Sus.div), Position Paper of Research Task, vol. 1, no. 2, 2006, pp. 1-45. www.pdfs.semanticscholar.org/b02a/e3746ce0ea1fd2c709a4fa7928a106610862.pdf?_ga $=2.78051607 .223459932 .1570955818-1387671198.1570955818$

Kadel, Pushker. "Reviewing Multilingual Education in Nepal." Multilingualisms and Development, edited by H. Coleman, British Council, 2017, pp. 189-204.

Khadka, Anju, Tikaram Chaudhary, Keshar Jung Magar, Ananda Chaudhary, and Rajan Pokhrel. Literacies from a Multi Lingual Perspective: Learning from Tharu, Tamang, Newar, and Limbu Language Communities of Nepal. UNESCO, 2006.

Khokhkova, Liudmila V. "Majority Language Death." Language Endangerment and Preservation in South Asia, edited by Hugo C. Cardoso, U of Hawai'i P, 2014, pp. 19-45.

Magwa, Wiseman. "Attitudes towards the Use of Indigenous African Languages as Languages of Instruction in Education: A Case of Zimbabwe." Journal of Educational Policy and Entrepreneurial Research (JEPER), vol. 2, no. 1, January 2015, pp. 1-16, file:///D:/UGC_RESEARCH/UGC\%20project\%20diversity\%202019/intl12\%20very\%20imp\%20-.pdf.

Majzub, Rohaty Mohd and Maisarah Muhammad Rais. "Perceptions of Students and Lecturers on the Preservation of Endangered Languages." Procedia Social and Behavioral Sciences, vol. 15, 2011, pp. 1877-1883.

file:///D:/UGC_RESEARCH/UGC\%20project\%20diversity\%202019/intl13\%20very\%20imp\%20-.pdf

Melton, Jeff. "Preserving Indigenous Languages: The Heart of Native America." University of Wisconsin-Superior McNair Scholars Journal, vol. 4, 2003, pp. 69-80.

Morey, Stephen. "Ahom and Tangsa: Case Studies of Language Maintenance and Loss in North East India." Language Endangerment and Preservation in South Asia, edited by Hugo C. Cardoso, U of Hawai'i P, 2014, pp. 46-77.

Pun, Min Bahadur, and Kamal Gurung. "Preserving Linguistic Diversity in Nepal: A Case of Indigenous Languages from Kaski District." Faculty Research Report, University Grants Commission, 2020.

Pun, Min Bahadur. "Language Death in Nepal: The Case of Indigenous Peoples with Reference to Magar Tongue." Journal of Indigenous Nationalities, vol. 13, no. 5, 2014, pp. 88-125. 
Regmi, Dan Raj. "Linguistic Surveys in Nepal: A Glimpse." T.U. Bulletin Special 2011-12, pp. 46-56.

- - -. "Convalescing the Endangered Languages in Nepal: Policy, Practice and Challenges." Gipan, vol. 3, no. 1, 2017, pp. 139-149.

Turin, Mark. Linguistic Diversity and the Preservation of Endangered Languages: A Case Study from Nepal. ICIMOD, 2007.

Watters, David, and Noval K. Rai. "Indigenous Languages of Nepal (ILN): Policy, Planning and Recommendations." The Indigenous Languages of Nepal (ILN): Situation, Policy Planning and Coordination, edited by Yogendra P. Yadava and Mark Turin, National Foundation for Development of Indigenous Nationalities (NFDIN), 2005, pp. 55-63.

Watters, Stephen, and Nirmal Man Tuladhar. "Indigenous Languages of Nepal: Capacity Building, Institutional Support and Coordination.” The Indigenous Languages of Nepal (ILN): Situation, Policy Planning and Coordination, edited by Yogendra P. Yadava and Mark Turin, National Foundation for Development of Indigenous Nationalities (NFDIN), 2005, pp. 74-83.

Wetzel, Arthur. "Preserving Linguistic Diversity in the Digital World." Multilingual, October 2018, pp. 38-42,

file://ID:/UGC_RESEARCH/UGC\%20project\%20diversity\%202019/intl-3\%20imp\%20.$p d f$

Xotta, Francesca. The Importance of Preserving Indigenous Languages: The Case of Guarani. U degli Studi di Padova, 2018.

Yadava, Yogendra P. "Language Use in Nepal.” Population Monograph of Nepal, vol. 2, Central Bureau of Statistics, 2014, pp. 51-72.

Yadava, Yogendra P., and Mark Turin. "Indigenous Languages of Nepal: A Critical Analysis of the Linguistic Situation and Contemporary Issues." The Indigenous Languages of Nepal (ILN): Situation, Policy Planning and Coordination, edited by Yogendra P. Yadava and Mark Turin, National Foundation for Development of Indigenous Nationalities (NFDIN), 2005, pp. 6-46. 